\title{
Collapse behaviour of compacted loess: role of the stress level on soil microstructure
}

\author{
Miaomiao Ge ${ }^{\mathrm{i} \text {,ii) }}$, Jubert A. Pineda ${ }^{\mathrm{iii}}$, Daichao Sheng ${ }^{\text {iv) }}$, Glen J. Burton ${ }^{\mathrm{v})}$ and Ning Li vi) \\ i) Ph.D Candidate, Priority Research Centre for Geotechnical Science and Engineering, School of Engineering, The \\ University of Newcastle, Callaghan Campus Building ES, Newcastle, NSW 2308, Australia \\ ii) Ph.D Candidate, School of Civil Engineering and Architecture, Xi'an University of Technology, Xi'an, China. 710048 \\ iii) Senior Lecturer, Priority Research Centre for Geotechnical Science and Engineering, School of Engineering, The \\ University of Newcastle, Callaghan Campus Building EA, Newcastle, NSW 2308, Australia \\ iv) Professor, Priority Research Centre for Geotechnical Science and Engineering, School of Engineering, The University \\ of Newcastle, Callaghan Campus Building EA, Newcastle, NSW 2308, Australia \\ v) Research Associate, Priority Research Centre for Geotechnical Science and Engineering, School of Engineering, The \\ University of Newcastle, Callaghan Campus Building EA, Newcastle, NSW 2308, Australia \\ vi) Professor, School of Civil Engineering and Architecture, Xi'an University of Technology, Xi'an, China. 710048
}

\begin{abstract}
The paper presents preliminary results of an experimental study aimed at evaluating the influence of soil microstructure on the collapse behaviour of compacted loess from Xi'an, Shannxi province, China. Collapse behaviour was evaluated from one-dimensional compression tests in which compacted specimens were loaded to different vertical stresses, under constant water content conditions, prior soaking. Mercury intrusion porosimetry (MIP) tests and Scanning Electron Microscopy (SEM) analysis reveals a strong influence of the stress level on the soil microstructure formed by soaking under zero lateral deformation conditions.
\end{abstract}

Keywords: Compacted loess, compression, soil collapse, soil microstructure

\section{INTRODUCTION}

Loess is a loosely cemented silty soil, transported and deposited by wind, formed in semi-arid continental climates. It covers an area around $13 \times 10^{6} \mathrm{~km}^{2}$ all over the world from which $631000 \mathrm{~km}^{2}$ are located in China, in the so-called Loess Plateau. The Loess Plateau runs along the Yellow River valley where natural deposits may reach thicknesses up to $300 \mathrm{~m}$ (Friedrich et al., 1982). The predominance of loess deposits in northern China, together with the rapid expansion of urban areas has led to its widespread use in several infrastructure projects mainly as filling material. Fill heights of hundreds of meters are now commonly found in local engineering projects.

Previous research has demonstrated that compacted loess exhibits important collapse upon wetting even though its natural microstructure is destroyed (e.g., Kim et al., 2013; Singhal et al., 2015). Therefore, issues like long-term deformation and differential settlements due to collapse (either by mechanical or hydraulic actions) are of high concern for most geotechnical infrastructure where compacted loess is used. Although some attempts have been made over the last decade to link the macroscopic response of unsaturated loess with microstructural information obtained from either qualitative and quantitative techniques (Jiang et al., 2012; Haeri, 2016, Li. et al. 2016; Liu et al. 2016; Muñoz-Castelblanco et al., 2013; Shao et al., 2018), a unified framework of behaviour is still not available.

This paper describes preliminary results of a comprehensive experimental program aimed at understanding the role of microstructure on the collapse behaviour of compacted loess from Xian, Shannxi province, China. One-dimensional compression tests are combined in this study with qualitative (Scanning Electron Microscopy, SEM) and quantitative (Mercury Intrusion Porosimetry, MIP) techniques to get additional insights on the mechanism of collapse for compacted loess.

\section{EXPERIMENTAL PROGRAM}

The material tested in this study is a clayey loess with clay and silt fractions equal to $21 \%$ and $77 \%$, respectively. This material classifies as low plasticity clay (CL) with a liquid limit of $36 \%$ and a plasticity index around $16 \%$. Index properties are summarized in Table 1.

\subsection{Compacted samples}

Natural loess was oven dried for $24 \mathrm{~h}$ before sieving through the $1.18 \mathrm{~mm}$ aperture sieve. Dry loess powder was then mixed with distilled water at a moisture 
content of $15 \%(2.5 \%$ less than the optimum from the standard proctor compaction test). The mixture was sieved through the $2.36 \mathrm{~mm}$ aperture sieve and then an equalization time of $24 \mathrm{~h}$ was allowed to achieve moisture equilibrium prior compaction.

Figure 2 shows the Standard Proctor compaction curve for the compacted loess, represented by a maximum dry density and optimum moisture content of $1.68 \mathrm{Mg} / \mathrm{m}^{3}$ and $17.5 \%$, respectively. Oedometer specimens (48 $\mathrm{mm}$ in diameter and $20 \mathrm{~mm}$ in height) were statically compacted to a dry density of 1.47 $\mathrm{Mg} / \mathrm{m}^{3}$ using a stress rate of $6 \mathrm{kPa} / \mathrm{min}$. This produced an as-compacted degree of saturation equal to $\mathrm{S}_{\mathrm{r}}=0.49$, a maximum compaction stress of $\sigma_{\text {comp }}=940 \mathrm{kPa}$ and an as-compacted suction (estimated using the filter paper method) around $\mathrm{s}=650 \mathrm{kPa}$. A filled square is used in Figure 2 to indicate the location the compaction state adopted in this study.

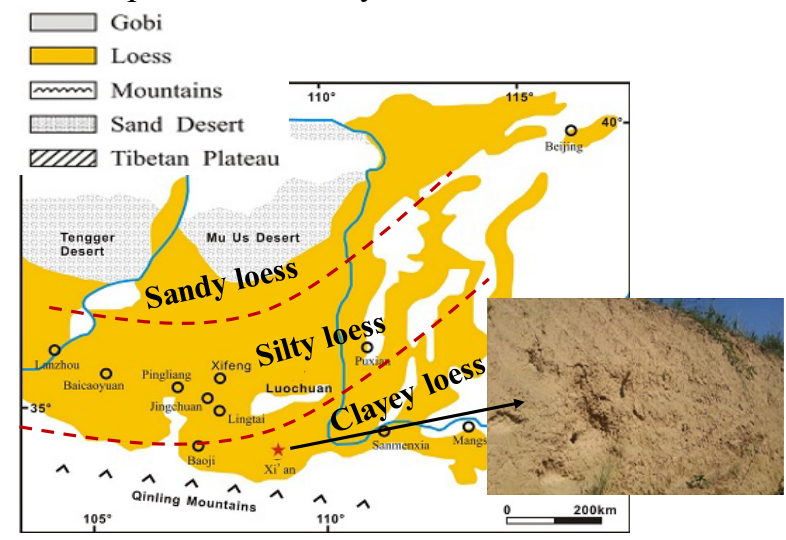

Fig. 1. Sampling site in Chinese Loess Plateau

Table 1. Index properties

\begin{tabular}{cc}
\hline Description & Value \\
\hline Soil type & CL \\
\hline Specific gravity, $G_{s}$ & 2.7 \\
\hline Clay fraction $(<2 \mu \mathrm{m})$ & 21 \\
\hline Silt fraction: $\%$ & 77 \\
\hline Sand fraction: $\%$ & 2 \\
\hline Liquid limit: $\%$ & 35.8 \\
\hline Plastic index: $\%$ & 15.6 \\
\hline $\begin{array}{c}\text { Standard Proctor maximum dry } \\
\text { density: } \mathrm{Mg} / \mathrm{m}^{3}\end{array}$ & 1.68 \\
\hline $\begin{array}{c}\text { Standard Proctor Optimum water } \\
\text { content: } \%\end{array}$ & 17.4 \\
\hline
\end{tabular}

Microstructure of the compacted loess was evaluated by means of Mercury Intrusion Porosimetry (MIP) tests and Scanning Electron Microscopy (SEM) analysis. MIP tests were performed in an AutoPore IV 9500 porosimeter (Micromeritics ${ }^{\circledR}$ ) whereas SEM microphotographs were obtained using a field emission microscope (Zeiss Sigma VP FESEM). In both tests, specimens were previously subjected to the freezedrying process following the procedure described in Delage et al. (2006). Figure 3 shows the initial (as- compacted) pore size density function (estimated from the derivative of the cumulative intrusion curve: $\left.\mathrm{PSD}=-\delta \mathrm{e}_{\mathrm{MIP}} / \log (d)\right)$ as a function of the pore size diameter, $d$. The as-compacted material shows a bimodal PSD with dominant pore diameters around 8-10 $\mu \mathrm{m}$ (macro porosity) and 0.2-0.4 $\mu \mathrm{m}$ (micro porosity). The inspection of the microphotograph shown in Figure 4 confirms that macro pores around $8 \mu \mathrm{m}$ are created by compaction. Aggregates seems to have a dominant pore size lower than $1 \mu \mathrm{m}$.

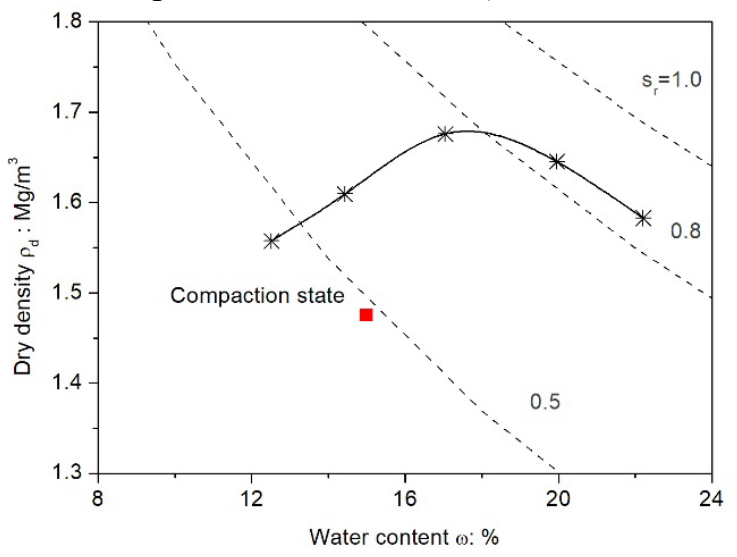

Fig. 2. Initial compaction state on the compaction plane

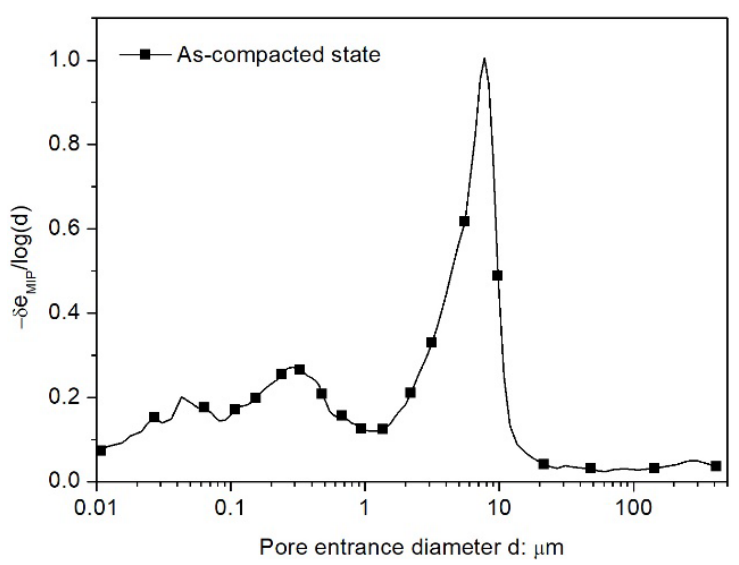

Fig. 3. Pore size distribution for as-compacted loess.

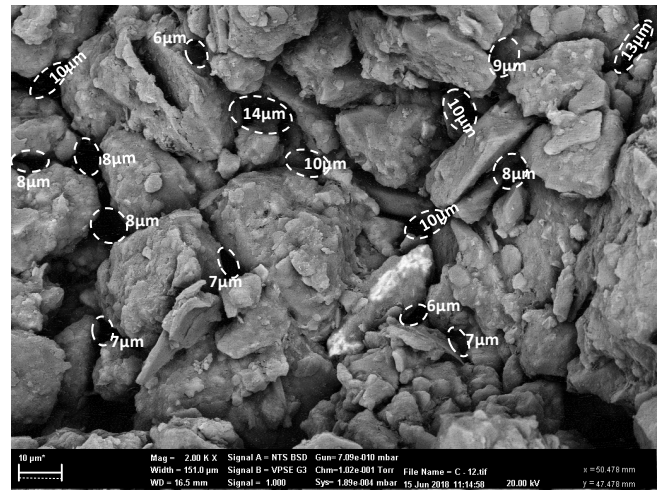

Fig. 4. SEM microphotograph for the as-compacted loess.

\subsection{Testing program}

The collapse behaviour of compacted loess was evaluated by means of one-dimensional (1D) 
compression tests. 1D incremental loading (IL) tests were conducted in a stainless steel oedometer apparatus equipped with bender elements for tracking the shear wave velocity of the specimen during loading and unloading paths. Each compression test consisted of four stages: (i) loading to target vertical stress under constant water content conditions, (ii) soaking at constant vertical stress, (iii) loading at saturated conditions to a maximum vertical effective stress of 1.6 $\mathrm{MPa}$, and (iv) unloading. Applied vertical stresses prior soaking were 13.5 (hereafter referred to as saturated sample), 50, 200, 400, 500, 900 and 1200 $\mathrm{kPa}$. A summary of the testing program is given in Figure 5. Solid circles are used to indicate the stress state at which MIP tests were performed to evaluate changes in soil microstructure.

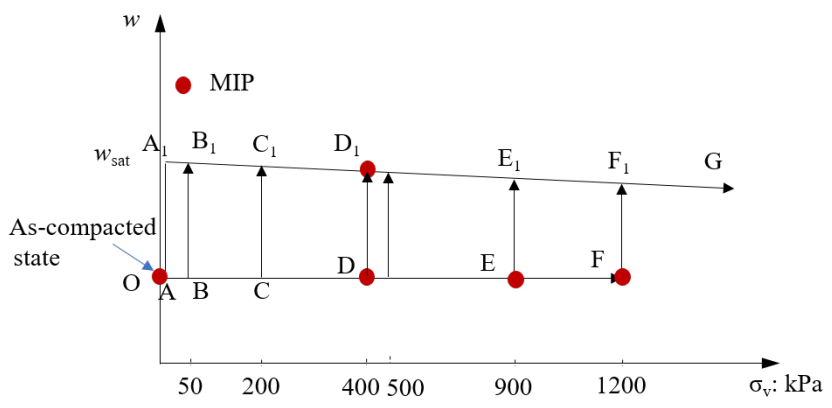

Fig. 5. Schematic description of the testing program

\section{TEST RESULTS}

The compressibility curves $e-\log \left(\sigma_{v}\right)$ obtained from 1D compression tests are shown in Figure 6. As expected, the saturated specimen (soaked at $13.5 \mathrm{kPa}$ ) shows larger compressibility compared to specimens loaded at unsaturated conditions prior soaking. Collapse upon soaking is observed in all specimens. It can be noted that the final void ratio achieved at the end of the soaking stage falls above the saturated compression curve. This behaviour is more evident for stresses larger than $200 \mathrm{kPa}$. The fact that specimens were soaked by applying a constant back pressure of $10 \mathrm{kPa}$ for three days before subsequent loading makes unlikely to presume that the smaller collapse upon soaking is caused by poor saturation $\left(\mathrm{S}_{\mathrm{r}}\right.$ estimated from water content and sample volume at the end of each test was always higher than 0.98). A more plausible explanation could be associated with differences in soil microstructure between saturated and soaked specimens. The unexpected larger compression observed in the next loading step after soaking, which tends to merge all the specimens with the compressibility curve of the saturated specimen, seems to support this hypothesis.

Figure 7 shows the evolution of the collapse strain upon soaking for different values of vertical stress. It may be noted that friction between the oedometer wall and the loading piston affected development of the collapse strain for the specimen soaked at $500 \mathrm{kPa}$. For all the remaining tests it can be seen that the collapse mechanism is composed of two stages. First, 'primary' collapse attributed here to the slippage of soil aggregates as capillary effects (menisci) disappear by the advance of the liquid water front. This phenomenon seems to be 'time-independent' as it occurs in a short period of time. Then, 'secondary' collapse in which a constant collapse strain-rate is achieved. Although the collapse strain-rate at this stage is much lower than the one measured during 'primary' collapse, its value seems to remain constant even after three days of equalization.

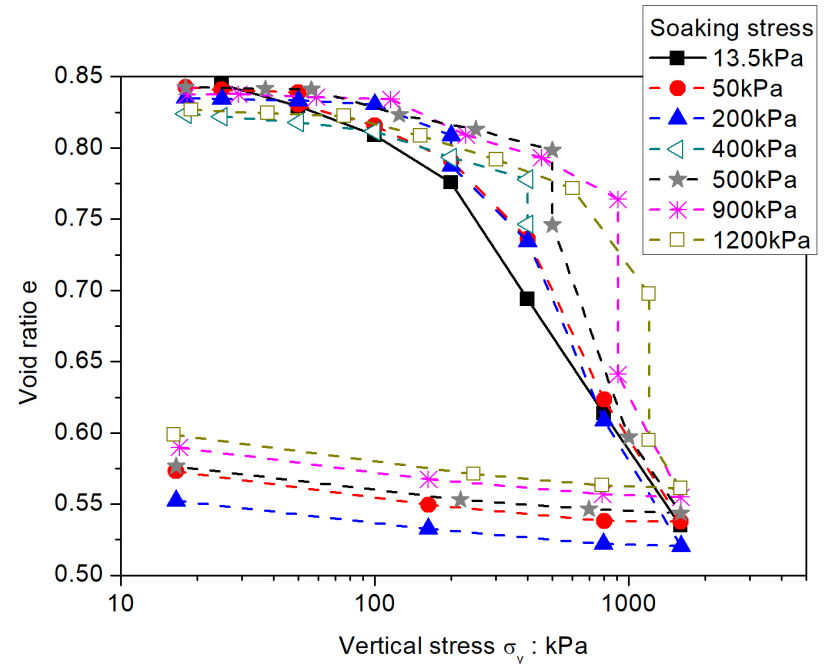

Fig. 6. Compressibility curves $e-\log \left(\sigma_{\mathrm{v}}\right)$ obtained from onedimensional compression tests

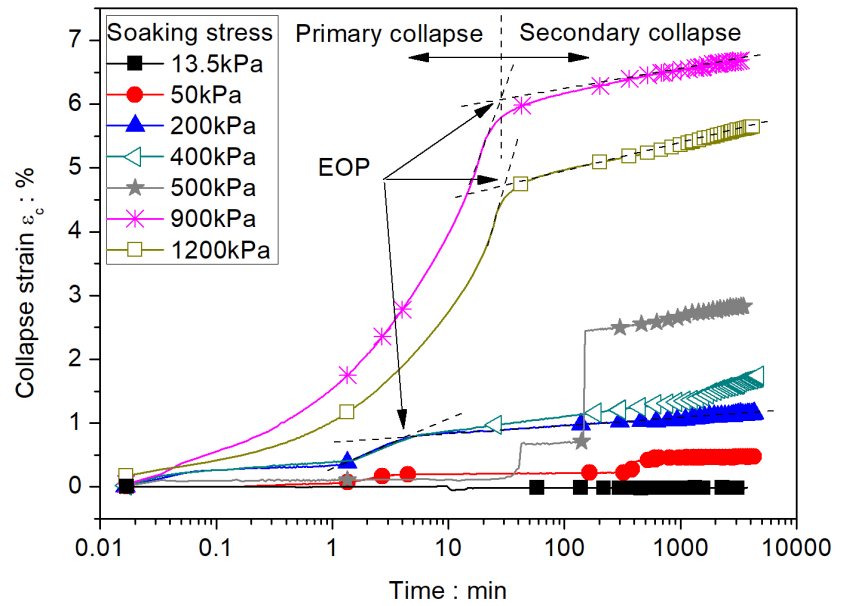

Fig. 7. Evolution of the collapse strain upon soaking

The maximum collapse strain measured at the end of the soaking stage is presented in Figure 8. A peak value around $6.8 \%$ is observed for a vertical stress of $900 \mathrm{kPa}$. This stress level is similar to the vertical stress applied during compaction $(940 \mathrm{kPa})$. A reduction in the maximum collapse strain occurs once the compaction stress is overcome owing to the increase in 
the degree of saturation (reduction in suction) by plastic compression. These results are qualitatively in agreement with previous data reported for natural and compacted loess (e.g. Phien-wej et al., 1992; MuñozCastelblanco et al., 2011; Shao et al., 2018).

Figure 9 shows the evolution of the recompression index $C_{\mathrm{r}}=-\Delta \mathrm{e} / \Delta \log \left(\sigma_{\mathrm{v}}\right)$ (for $\sigma_{\mathrm{v}}<\sigma_{\text {yield }}$ ) as well as the compression index $C_{c}=-\Delta \mathrm{e} / \Delta \log \left(\sigma_{v}\right)\left(\right.$ for $\left.\sigma_{v}>\sigma_{\text {yield }}\right)$, estimated from the compressibility curves presented in Figure 6. Inspection of Figure 6 suggests a value of $\sigma_{\text {yield }}^{\prime}$ around $180 \mathrm{kPa}$ for the saturated sample. Vertical arrows are used in Figure 9 to indicate the stress level prior soaking. It may be noted that the degree of saturation of each specimen prior soaking is also included in this figure. As expected, minor increase in $\mathrm{S}_{\mathrm{r}}$ is observed upon loading at constant water content. $\mathrm{S}_{\mathrm{r}}$ increases from 0.49 to 0.53 when the vertical stress reaches $900 \mathrm{kPa}$. Further loading to $1200 \mathrm{kPa}$ causes larger increase in $\mathrm{S}_{\mathrm{r}}$ to 0.58 owing to plastic compression. $\mathrm{C}_{\mathrm{r}}$ varies between 0.001 and 0.1 with an upper bound delimited by the saturated sample. Contrary to $\mathrm{C}_{\mathrm{r}}$, the upper bound for $\mathrm{C}_{\mathrm{c}}$ is not given by the saturated sample. A peak value, located above the saturated line, is observed in Figure 9 at $\sigma_{\mathrm{v}}=900 \mathrm{kPa}$. This is caused by the strong compression measured in the next loading step after soaking (see Figure 6). Subsequent loading steps provide values of $\mathrm{C}_{c}$ in agreement with the saturated specimen.

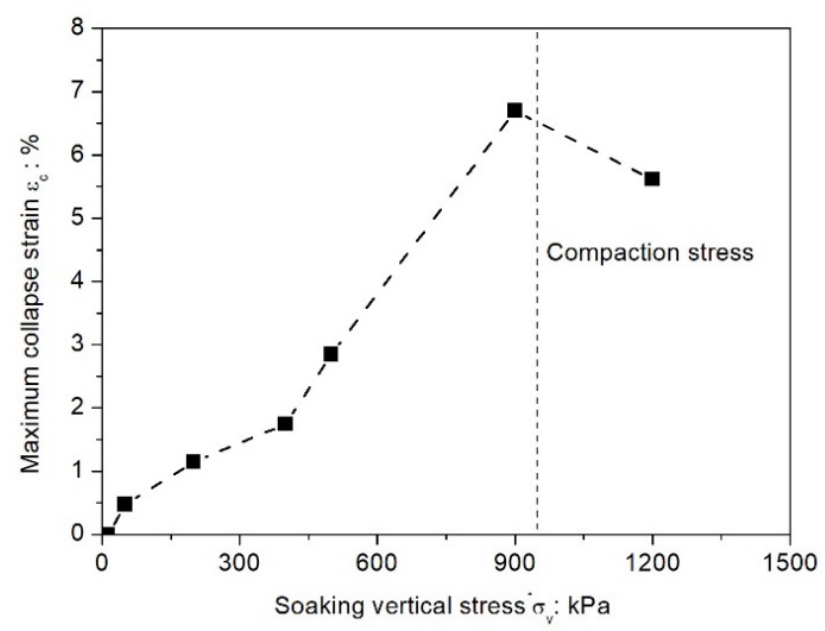

Fig. 8. Maximum collapse strain vs versus vertical stress

The evolution of the secondary compression index $\mathrm{C}_{\alpha}=-\Delta \mathrm{e} / \Delta \log (\mathrm{t})$ with the stress level is shown in Figure 10. $C_{\alpha}$ increases with the stress level for both saturated and unsaturated states. Lower values of $\mathrm{C}_{\alpha}$ are obtained in unsaturated specimens due to the stiffening effect of soil suction. Arrows represent the change in $\mathrm{C}_{\alpha}$ induced by soaking at constant vertical stress. For a given vertical stress, the $\mathrm{C}_{\alpha}$ estimated from the last $24 \mathrm{~h}$ of soaking is much larger than the value obtained for the saturated specimen (black squares). This result in combination with the larger $\mathrm{C}_{\mathrm{c}}$ obtained in the next loading step after soaking may be explained by a 'metastable' microstructure generated by partial collapse upon soaking.

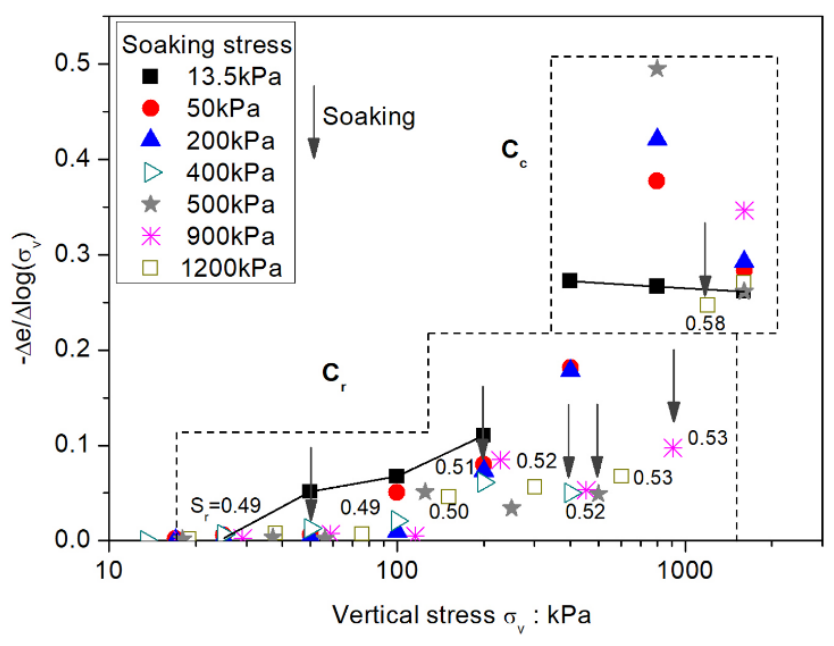

Fig. 9. Variation of the recompression index $C_{r}$ and the compression index $\mathrm{C}_{\mathrm{c}}$ with vertical stress

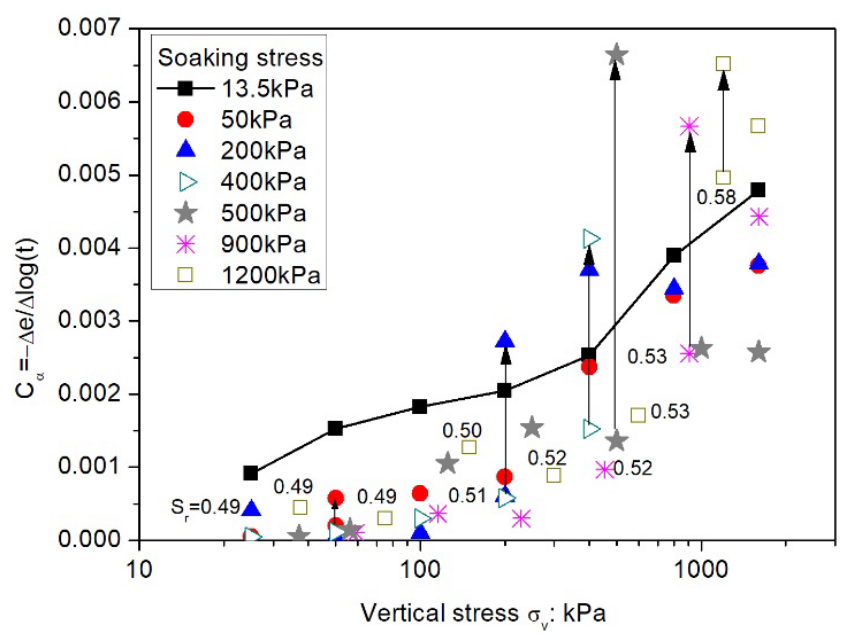

Fig. 10. Variation of the secondary compression coefficient $C_{a}$ with vertical stress

MIP tests were carried out on specimens subjected to $1 \mathrm{D}$ compression (before and after soaking) in order to get further insights on the mechanism of collapse in compacted loess. Figure 11 shows the PSD curves obtained for specimens compressed to vertical stresses of 400,900 and $1200 \mathrm{kPa}$ under constant water content conditions. The PSD for the as-compacted state is also included in this figure as reference. Although 1D compression causes a reduction in the peak density with increasing the vertical stress, the results shown in Figure 11 indicate that the bi-modal PSD is preserved. 


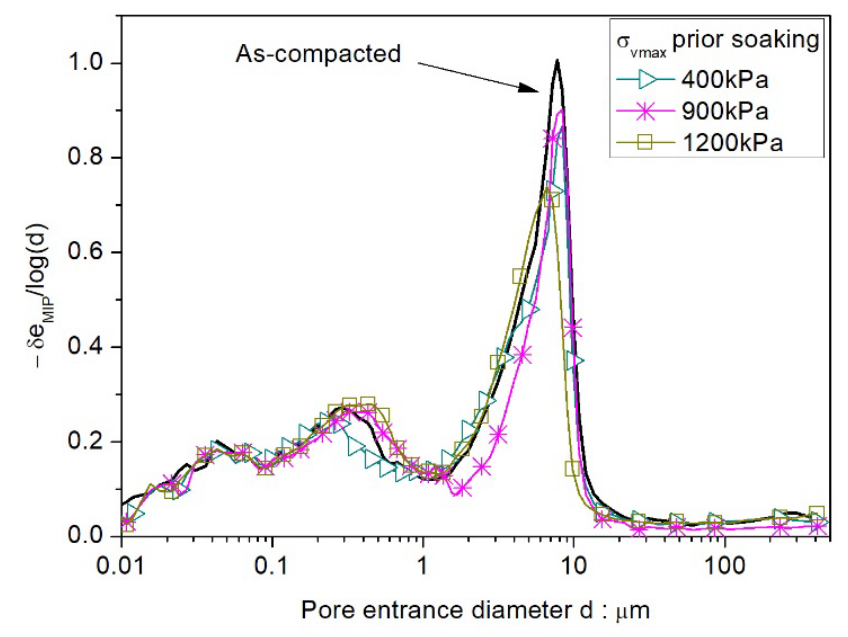

Fig. 11. PSD for specimens loaded to three different vertical stresses under constant water content conditions

Important changes in soil microstructure are observed in Figure 12, which shows PSD curves for three specimens loaded up to $400 \mathrm{kPa}$ following different mechanical and hydraulic paths. Black filled squares represent the PSD for the saturated specimen (i.e. soaked at $13.5 \mathrm{kPa}$ ). Empty circles refer to one specimen loaded up to $400 \mathrm{kPa}$ at constant water conditions whereas empty triangles represent a specimen compressed to $400 \mathrm{kPa}$ at constant water content conditions then soaked for three days. It can be seen that soaking produces a reduction in the dominant pore size from $8 \mu \mathrm{m}$ to $3.5 \mu \mathrm{m}$ due to collapse of the soil structure. However, such a collapse is not able to create a PSD similar to the one for saturated soil, which displays a dominant pore size about a half of the soaked specimen $(1.7 \mu \mathrm{m})$. The range of pore sizes covered by the saturated specimen is lower than the soaked sample. This indicates that these two specimens, both saturated and compressed to the same vertical stress, have different soil microstructures. MIP results indicate that only partial collapse of the macropores takes place in soaked specimens. This behaviour creates a 'meta-stable' microstructure which tends to collapse further during the next loading step. Additional experimental results, obtained on specimens compacted to different densities and water contents, are needed to confirm the hypothesis presented in this paper.

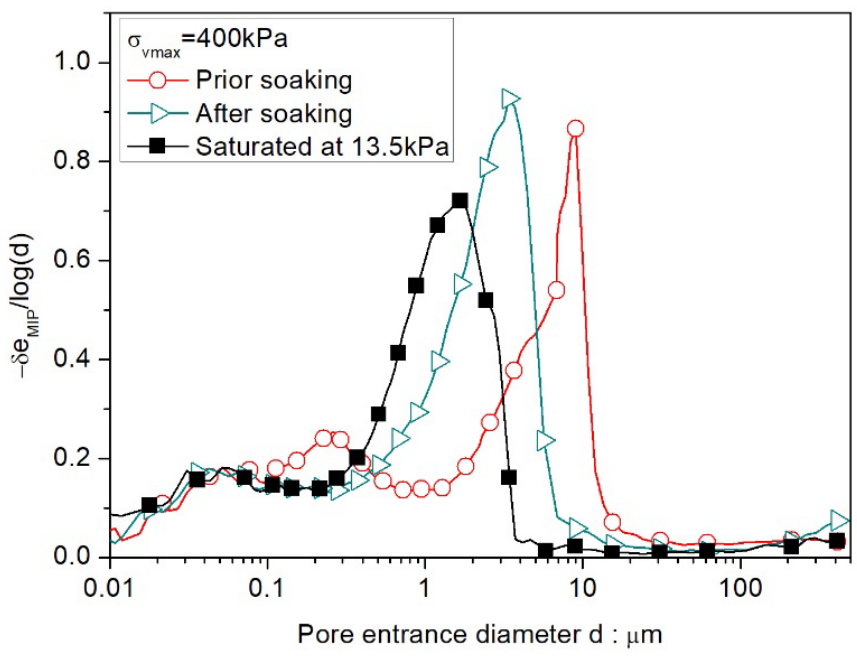

Fig. 12. PSD for specimens loaded to $400 \mathrm{kPa}$ and then subjected to different saturation states.

\section{CONCLUSIONS}

The collapse behaviour of a compacted clayey loess from Shanxi province (China) was evaluated in this paper. Emphasis was given to the role of the stress level on soil microstructure as it seems to control the collapse behaviour of the compacted loess.

Partial collapse upon soaking at constant vertical stress was observed in 1D compression tests with the void ratio obtained at the end of the soaking stage remaining above the saturated compression curve. However, values of secondary compression index $\mathrm{C}_{\alpha}$ much larger than those estimated for the saturated soil were recorded in the last $24 \mathrm{~h}$ of the soaking stage. Moreover, large compression was observed in the next loading step after soaking which led to values of the compression index $\mathrm{C}_{\mathfrak{c}}$ larger than the saturated material. Macroscopic results suggested that soaking tends to produce a 'meta-stable' microstructure able to collapse further as soon as additional load is applied. The comparison of the PSD curves obtained from MIP tests provided evidence of the differences in soil microstructure between specimens soaked at different vertical stresses, which partly explains the macroscopic results described above.

\section{ACKNOWLEDGEMENTS}

The present study is part of the first author's PhD work that is partially supported by the China Scholarship Council (scholarship no. 201708610105).

\section{REFERENCES}

1) Chandler, R. J., Crilly, M. S. and Smith, M. G. (1992): A low-cost method of assessing clay desiccation for low-rise buildings, Proceedings of the Institution of Civil Engineers-Civil Engineering, 92, May, 82-89.

2) Delage, P., Cui, Y. J., and Antoine, P. (2005): Geotechnical problems related with loess deposits in Northern France, Proceedings of International Conference on Problematic Soils, Eastern Mediterranean University, Famagusta, N. 
Cyprus, 25-27.

3) Friedrich, H., Liu, T. S. (1982): Magnetostratigraphical dating of loess deposits in China, Nature, 300 (5891). 431433.

4) Haeri, S. M. (2016): Hydro-mechanical behavior of collapsible soils in unsaturated soil mechanics context, The 15th Asian Regional Conference on Soil Mechanics and Geotechnical Engineering, 2(1). 25-40.

5) Jiang, M., Hu, H. and Liu, F. (2012): Summary of collapsible behaviour of artificially structured loess in oedometer and triaxial wetting tests, Canadian Geotechnical Journal, 49(10), 1147-1157.

6) Kim, D. \& Kang, S. S. (2013): Engineering properties of compacted loesses as construction materials, KSCE Journal of Civil Engineering, 17(2), 335-341.

7) Li, P., Vanapalli, S. and Li, T. L. (2016): Review of collapse triggering mechanism of collapsible soils due to wetting, Journal of Rock Mechanics and Geotechnical Engineering, $8,256-274$

8) Liu, Z., Liu, F. Y., Ma, F. L. et al. (2016): Collapsibility, composition, and microstructure of loess in China, Canadian Geotechnical Journal, 53, 673-686.

9) Muñoz-Castelblanco, J., Delage, P., Pereira, J. M. et al. (2011): Some aspects of the compression and collapse behaviour of an unsaturated natural loess, Géotechnique Letters, 1, 17-22.

10) Muñoz-Castelblanco, J., Delage, P., Pereira, J. M. et al. (2013): Collapse behaviour of a natural loess from Northern France, Proc. 1st PanAmUnsat Conference, Cartagena de los Indias, Colombia, 315-319.

11) Phien-wej, N., Pientong T., Balasubramaniam, A. S. (1992): Collapse and strength characteristics of loess in Thailand, Engineering Geology, 32, 59-72.

12) Singhal, S., Sharma, R. S. and Phanikumar, B. R. (2015): A laboratory study of collapse behaviour of remoulded loess under controlled wetting and flooding, Geomechanics and Geoengineering, 11(2), 159-163.

13) Shao, X. X., Zhang, H. Y. and Tan, Y. (2018): Collapse behavior and microstructural alteration of remolded loess under graded wetting tests, Engineering Geology, 233, 1122. 